UNIVERSIDADE DE SÃO PAULO

FACULDADE DE ECONOMIA, ADMINISTRAÇÃO E CONTABILIDADE DEPARTAMENTO DE ECONOMIA

PROGRAMA DE PÓS-GRADUAÇÃO EM ECONOMIA

UM TESTE EMPÍRICO PARA MUDANÇAS EM NÍVEIS PARA PRECIFICAÇÃO DE ATIVOS

Eduardo De Nardi Ros

Orientador: Prof. Dr. Mauro Rodrigues Jr.

SÃO PAULO 
Prof. Dr. João Grandino Rodas

Reitor da Universidade de São Paulo

Prof. Dr. Reinaldo Guerreiro

Diretor da Faculdade de Economia, Administração e Contabilidade

Prof. ${ }^{a}$ Dr ${ }^{a}$ Elizabeth Maria Mercier Querido Farina

Chefe do Departamento de Economia

Prof. Dr. Pedro Garcia Duarte

Coordenador do Programa de Pós-Graduação em Economia 


\section{UM TESTE EMPÍRICO PARA MUDANÇAS EM NÍVEIS PARA PRECIFICAÇÃO DE ATIVOS}

Dissertação apresentada ao Departamento de Economia da Faculdade de Economia, Administração e Contabilidade da Universidade de São Paulo como requisito para obtenção do título de Mestre em Ciências.

Orientador: Prof. Dr. Mauro Rodrigues Jr.

\section{Versão Original}

\section{SÃO PAULO}


FICHA CATALOGRÁFICA

Elaborada pela Seção de Processamento Técnico do SBD/FEA/USP

Ros, Eduardo De Nardi

Um teste empírico de mudanças em níveis para precificação de ativos / Eduardo De Nardi Ros. -- São Paulo, 2012. $36 p$.

Dissertação (Mestrado) - Universidade de São Paulo, 2012.

Orientador: Mauro Rodrigues Junior.

1. Financas 2. Economia internacional 3. Preços I. Universidade de São Paulo. Faculdade de Economia, Administração e Contabilidade. II. Título.

CDD -332 
À minha avó Zilah de Freitas Ros 
Foi a minha amada avó Zilah de Freitas Ros quem me ensinou a primeira teoria econômica que aprendi, a qual me serve de inspiração frequentemente: "a forma mais valiosa de riqueza é o conhecimento". É dona do meu mais especial agradecimento.

Agradeço aos meus pais Sady Freitas Ros e Margot De Nardi Ros, de quem herdei muito mais que a genética. Não tenho sequer uma característica comportamental - que são justamente as que nos definem - a qual não tenha sido por eles forjada. Ao meu irmão, agradeço por transmitir sua alegria.

Sou grato a minha Pequena pela imensa paciência, por caminhar cada passo ao meu lado nestes três anos e oito meses, por seu amor e por sua crença nos meus sonhos. Agradeço aos seus pais Antônio Rodrigues Patricio e Sandra Maria Ribeiro Patricio pelo carinho e confiança.

Ao Fred, “irmão-pai” que a vida me deu, agradeço por anos de amizade, conselhos, conversas e muita alegria. Inesquecível ter me acolhido em sua casa, onde ganhamos uma Libertadores com o pé-quente Coletti, a quem agradeço por dar abrigo ao famoso “cabritinho".

Aos queridos amigos Cegonha e Zilio, que além dos momentos de amizade também me acolheram em suas casas, muito obrigado. Agradeço imensamente a todos os membros do Partidinho: Sérgio, Meloni, Marcel, Pitt, Marião, Pino, Gato, Gênio, Heleno, Cegonha, Victão e Zilio. Vocês foram capazes de tornar o temido primeiro semestre um dos momentos mais felizes da minha vida. O que para muitos foi uma carga penosa, para mim foi uma grande diversão regada à espuma persistente e consistente. Agradeço especialmente ao Paulo pelos diálogos corretos, por me agraciar com seus argumentos logicamente consistentes e por seus necessários conhecimentos econométricos.

Agradeço especialmente ao meu orientador Mauro Rodrigues Jr. por dois momentos. As aulas de macroeconomia: interessantes, didáticas, instigantes e motivadoras; e a orientação dedicada e competente neste trabalho. Por ter tornado possível a minha admissão no curso de mestrado do IPE, agradeço ao professor Jorge Araújo.

Agradeço, finalmente, ao IPE, à FEA e à USP pelo excelente curso de mestrado. Agradeço também à FAPESP pelo financiamento deste trabalho e ao CNPq pela bolsa de mestrado. Em nome da USP e da FAPESP, agradeço a toda sociedade paulista. 
“A razão não é automática, aqueles que a renegam não podem ser conquistados por ela." 


\section{RESUMO}

O objetivo deste trabalho é realizar um teste empírico da teoria de precificação de ativos em um conjunto de países. Em geral, a literatura utiliza testes para o modelo CAPM a partir de uma cross-section de ativos, encontrando evidências que vão tanto ao seu encontro como o refutam. No presente trabalho, entretanto, utiliza-se um teste de mudanças no nível de exposição ao risco sistemático, de maneira similar a Chari e Henry (2004). O experimento natural será a concessão (ou perda) de grau de investimento das principais agências de risco. A hipótese é que ativos sujeitos a novo nível de risco sistemático devem ter seu retorno alterado de acordo com as respectivas magnitudes individuais das diferenças no nível de exposição ao risco sistemático. Os resultados confirmam o que se espera ao examinar-se a teoria. 


\begin{abstract}
The objective of this dissertation is to perform an empirical test of the asset pricing theory in a set of countries. The literature usually tests CAPM from a cross-section, finding evidence that both confirm and refute theory predictions. In the present dissertation change in levels are used to test CAPM, similar to Chari and Henry (2004). The natural experiment is the countries' rate upgrade to investment grade or downgrade to speculative grade by major ratings agencies. The hypothesis is that return of assets subject to a change in levels of systematic risk should be amended in accordance with their respective magnitudes of individual differences in exposure to systematic risk. The results confirm theory predictions.
\end{abstract}





\section{SUMÁRIO}

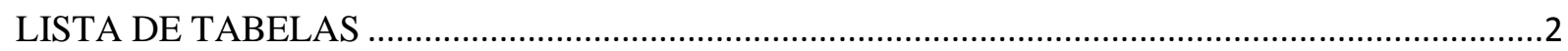

LISTA DE GRÁFICOS

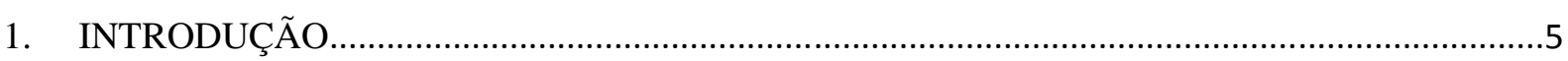

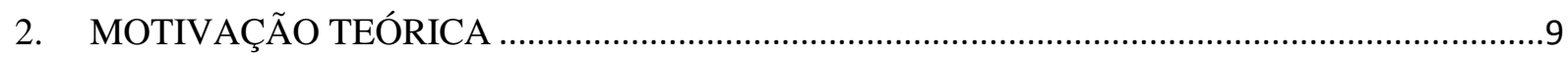

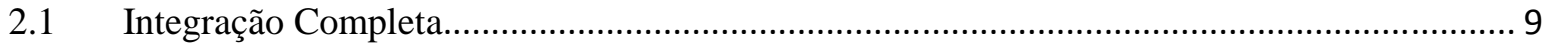

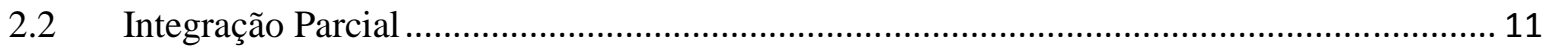

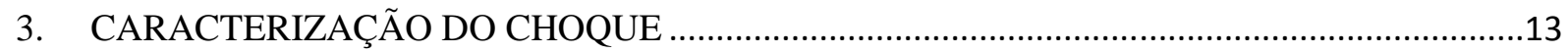

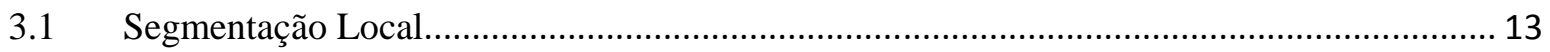

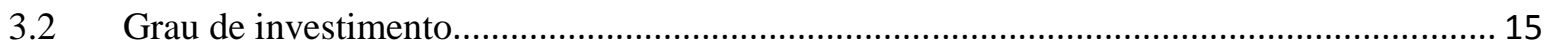

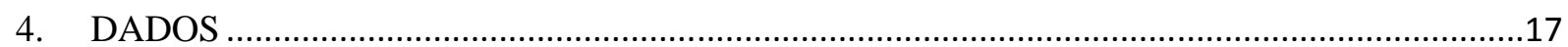

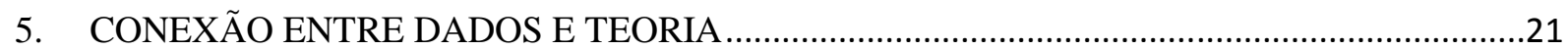

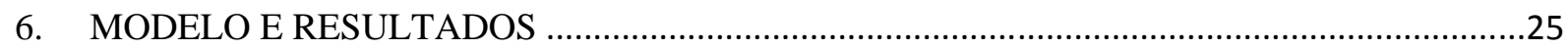

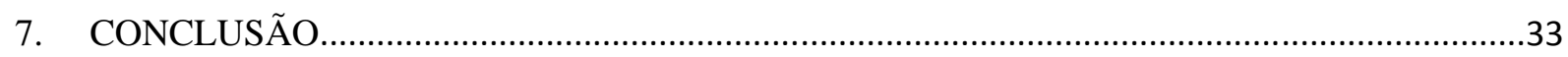

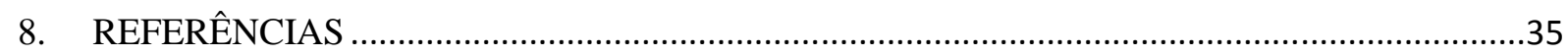




\section{LISTA DE TABELAS}

Tabela 1 - Datas de Grau de Investimento por País ............................................................ 18

Tabela 2 - Datas de Rebaixamento por País .................................................................. 18

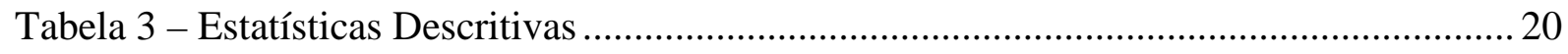

Tabela 4 - Primeiro e Segundo Evento de Elevação de Nota.................................................. 26

Tabela 5 - Primeiro e Segundo Evento de Rebaixamento de Nota ......................................... 27

Tabela 6 - Resultados Adicionais para o Choque de Integração .......................................... 30

Tabela 7 - Resultados Adicionais para o Choque de Segmentação ........................................ 31 


\section{LISTA DE GRÁFICOS}

Gráfico 1 - Segunda Elevação para Grau de Investimento................................................ 21

Gráfico 2 - Segundo Rebaixamento de Grau de Investimento ........................................... 23 


\section{INTRODUÇÃO}

Segundo a teoria de precificação de ativos, a alocação do capital se dá de forma a igualar os retornos dos ativos controlados por seu risco. Por conseguinte, os ativos serão precificados conforme o seu grau de exposição ao risco sistemático (SHARPE, 1964), teoria denominada de Capital Asset Pricing Model - CAPM -, desenvolvida independentemente por Sharpe e Lintner na década de 1970, cuja ampla aceitação está relacionada ao argumento intuitivo da teoria (FAMA AND FRENCH, 2004). Embora a teoria afirme que os retornos esperados dos ativos devam variar no nível de acordo com o grau de exposição ao risco, segundo Fama (1991), Campbell (2000) e Cochrane (1999), há pouca evidência de que a exposição ao risco sistemático é precificada no nível.

Enquanto a literatura concentra-se em testar o retorno de um conjunto de ativos em um determinado momento, a chamada abordagem nos níveis, Chari e Henry (2004) propuseram a abordagem utilizada neste trabalho: testar a teoria em mudanças de níveis, ou seja, verificar a capacidade da teoria de explicar variações no retorno de um ativo quando ocorre uma alteração significativa no seu grau de exposição ao risco sistemático. A metodologia utilizada para isso é o uso de um experimento natural: mudança de classificação de risco em torno do grau de investimento ${ }^{1}$.

Os países são classificados por agências de classificação de risco ${ }^{2}$ de acordo com seu risco de crédito: a cada nível de risco se atribui uma nota (rating). Quando um país atinge um patamar de risco suficientemente baixo, que corresponde a um nível de notas alto, passa a integrar o grupo de países de menor risco do mundo: países grau de investimento. A concessão de grau de investimento, portanto, sinaliza que o risco do país que a recebe é baixo ao colocá-lo no grupo de países grau de investimento. Da mesma forma, o rebaixamento de um país o retire deste grupo e sinaliza que o mesmo já não está entre os países com menor risco no mundo.

\footnotetext{
${ }^{1}$ Grau de investimento é um conjunto de ratings soberanos. Quando o risco soberano de um país passa a ser classificado neste conjunto, diz-se que lhe foi concedido grau de investimento.

${ }^{2}$ Agências de classificação de risco são empresas que analisam o risco de firmas, países e outros emissores de dívida.
} 
Destarte, esta concessão (ou perda) de grau de investimento altera a percepção de risco sistemático e, segundo a teoria, deve impactar no retorno dos ativos sujeitos a esse, sendo este impacto específico para cada ativo. Esta mudança de percepção se deve ao fato de que a concessão de grau de investimento eleva o investimento dos investidores institucionais no país que a recebe. Então, os ativos passam a ser expostos a outro nível de risco sistemático e seus preços se modificam de forma a ajustar o retorno específico em relação ao risco, já que segundo a teoria de precificação de ativos, o capital é alocado de forma que os retornos ajustados por seus respectivos riscos são igualados entre os ativos. A concessão de grau de investimento atua como um choque de integração de mercados, enquanto a perda desta atua como um choque de segmentação.

De acordo com a teoria, o efeito dessa mudança é específico para cada firma. Quando ocorre o evento, as alterações nos retornos esperados devem ser proporcionais ao sentido da mudança de risco. Portanto, para uma firma que experimenta uma queda no retorno esperado a expectativa é que seu preço suba - uma vez que retornos esperados se refletem no preço - e que sua exposição ao risco caia. Como retornos são observáveis e exposição ao risco pode ser mensurada, é possível testar a teoria.

Define-se DIFCOV como a diferença entre a covariância entre o retorno específico do ativo com o retorno do mercado local e a covariância do mesmo retorno específico com o mercado global. Desta forma, obtém-se uma medida para a mudança de nível de risco sistemático, e, ceteris paribus, ativos com maiores DIFCOV devem ter maior reprecificação, com sentido positivo para concessão e negativo para perda do grau de investimento.

A análise feita neste trabalho avalia se o efeito de mudança de nível de risco afeta a reprecificação através de uma regressão entre a alteração nos preços das empresas (que medem a alteração do retorno esperado) e os DIFCOV (que medem a mudança no nível de risco sistemático), controlados por efeito específico de cada país. São utilizados dados de 3.266 firmas de 9 diferentes países.

A regressão base deste trabalho confirma as predições teóricas: ativos sujeitos a novo nível de risco sistemático devem ter seu retorno alterado de acordo com as respectivas 
magnitudes individuais das diferenças de nível de exposição ao risco sistemático, nos sentidos acima mencionados. Firmas com maior DIFCOV, portanto, experimentam maior reprecificação tanto para o evento de concessão quanto para o evento de rebaixamento, segundo os resultados.

A análise de dados de ativos em detrimento de dados agregados se justifica a partir dos poucos graus de liberdade que o uso de dados agregados fornece, já que observamos apenas um dado agregado para cada evento. Embora covariâncias contenham frequentes erros de medida, que potencialmente comprometem o poder das regressões, espera-se que o impacto da concessão de grau de investimento seja suficientemente grande para tornar os ruídos oriundos desses erros de medida desprezíveis. Desta forma, justifica-se o teste de mudança de nível de exposição ao risco sistemático em relação à mudança no nível (Chari e Henry, 2004).

A reprecificação pode estar relacionada a aspectos específicos das empresas que não a sua diferença de nível de exposição ao risco sistemático. Basu (1977) encontrou evidências de que a razão entre os lucros pagos por uma ação e o seu preço - earning yield - possui poder explicativo marginal sobre o retorno esperado desta ação, mesmo após controlar pelo beta. Segundo Banz (1981), o tamanho da firma pode explicar seu retorno. Basu (1983) e Rosenberg, Reid e Lanstein (1985) mostraram que a razão entre o valor de mercado de uma ação e o valor patrimonial ${ }^{3}$ tem explicação marginal sobre o retorno do ativo quando controlado pelo grau de exposição ao risco sistemático, da mesma forma que Bhandari (1988) fez para o grau de alavancagem ${ }^{4}$ de uma empresa. Finalmente, Fama e French (1992) publicaram um artigo que mostra que todas as variáveis dos artigos mencionados possuem poder explicativo marginal sobre o retorno quando este é controlado por beta. Neste mesmo artigo, surgiu talvez o mais contundente resultado que refuta o CAPM: foi mostrado que o beta não possui poder explicativo sobre o retorno destes ativos, mesmo quando é a única variável explicativa utilizada.

Chari e Henry (2004) efetuaram testes considerando o efeito destas variáveis: raramente encontraram efeitos significantes na explicação das reprecificações, em estimação

\footnotetext{
${ }^{3}$ Razão entre o patrimônio líquido e o número de ações.

${ }^{4}$ Razão entre o passivo total e valor de mercado do total de ações.
} 
conjunta com a variável DIFCOV. Embora essas variáveis possam ter poder explicativo, o presente trabalho se destina a testar a versão original do CAPM, sem verificar o seu efeito.

Este trabalho, por outro lado, contribui com a abordagem de mudanças de nível de exposição a risco sistemático, proposta por Chari e Henry (2004) que utilizaram em seu trabalho o choque de liberalização e consequente abertura dos mercados financeiros. Diferentemente dos proponentes desta abordagem que, devido à natureza do evento de liberalização, observaram um lado do choque, o evento grau de investimento utilizado neste trabalho permite a contribuição de observar dois lados do choque: concessão e rebaixamento.

O impacto da mudança de rating é assunto que interessa a literatura. Autores analisam os efeitos de mudanças em ratings soberanos (Cantor e Packer, 1996) e em ratings corporativos (Da e Gao, 2009; Kingsen, 2006; Chuhan, 1994). Estes autores encontram e observam evidências de que grau de investimento é um evento relevante para o apreçamento dos ativos. Embora não seja objeto de interesse deste trabalho testar os efeitos do grau de investimento, se observa nos resultados o efeito que os preços das firmas sofrem por razão da mudança de nível de exposição ao risco de um evento de alteração de nota soberana de crédito, especificamente em torno do grau de investimento. 


\section{MOTIVAÇÃO TEÓRICA}

A motivação teórica é baseada em Stulz (1999a), Errunza e Losq (1985) e Chari e Henry (2004). Considere o ambiente de um país suficientemente pequeno e cujo mercado de ativos é completamente segmentado do mercado de ativos global. Suponha ainda que os indivíduos sejam idênticos - possuem idêntica aversão ao risco -, e se importam apenas com a expectativa e variância do retorno de seus portfólios. Desta forma, o coeficiente de aversão a risco no país é constante - denotado por $\gamma$-, e o CAPM é válido. É possível, portanto, escrever:

$$
E\left[R_{i}\right]=r_{f}+\beta_{i j} \sigma_{j}^{2} \gamma
$$

Onde:

- $E\left[R_{i}\right]$ é o retorno esperado do ativo i.

- $\quad r_{f}$ é a taxa livre de risco.

- $\quad \beta_{i j}$ é o coeficiente beta ${ }^{5}$ para a firma i do país j, antes da concessão, em relação ao mercado local.

- $\sigma_{j}$ é a variância do retorno do portfólio do país $j$.

\subsection{Integração Completa}

Passe a considerar os impactos de uma integração completa, isto é, tanto investidores estrangeiros passam a poder investir no país, como investidores locais podem, então, investir fora do país. Suponha, para a consideração dos impactos, que o retorno

\footnotetext{
${ }^{5}$ Coeficiente beta é o coeficiente da regressão linear do retorno do ativo específico contra o retorno do mercado.
} 
esperado e a variância dos lucros das firmas locais não são afetados pelo evento de integração. Suponha, ainda, que os investidores estrangeiros possuem idêntica aversão a risco que os investidores locais.

Por meio deste evento, o risco sistemático relevante para o investidor altera-se do portfólio local para o portfólio global. Então, pode-se escrever que:

$$
E\left[R_{i}^{*}\right]=r_{f}^{*}+\beta_{i w} \sigma_{w}^{2} \gamma
$$

Onde:

- $E\left[R_{i}^{*}\right]$ é o retorno esperado do ativo i após a integração com o mercado global.

- $r_{f}^{*}$ é a taxa livre de risco global.

- $\quad \beta_{i w}$ é o coeficiente beta para a firma i com o mercado global.

- $\sigma_{w}$ é a variância do retorno do portfólio global.

Considere que $\beta_{i w}=\frac{\operatorname{cov}\left(R_{i}, R_{w}\right)}{\operatorname{var}\left(R_{w}\right)}$ e $\beta_{i j}=\frac{\operatorname{cov}\left(R_{i}, R_{j}\right)}{\operatorname{var}\left(R_{j}\right)}$. Desta forma, é possível escrever (1) e (2), respectivamente, conforme segue:

$$
\begin{aligned}
& E\left[R_{i}\right]=r_{f}+\gamma \operatorname{cov}\left(R_{i}, R_{j}\right) \\
& E\left[R_{i}^{*}\right]=r_{f}^{*}+\gamma \operatorname{cov}\left(R_{i}, R_{w}\right)
\end{aligned}
$$

Subtraia (4) de (3):

$$
\Delta R_{i}=E\left[R_{i}\right]-E\left[R_{i}^{*}\right]=r_{f}-r_{f}^{*}+\not D I F C O V
$$


Onde $D I F C O V=\operatorname{cov}\left(R_{i}, R_{j}\right)-\operatorname{cov}\left(R_{i}, R_{w}\right)$.

A variável $D I F C O V$ fornece a medida de variação no grau de exposição ao risco sistemático, específico para cada firma. É o canal idiossincrático pelo qual firma i é afetada pela alteração no grau de risco sistemático. O outro canal é a diferença das taxas livres de risco, comum a todas as empresas de determinado país.

\subsection{Integração Parcial}

Considere integração parcial o evento que permite ao investidor estrangeiro investir de forma irrestrita no país, enquanto que ao investidor local só é permitido investir localmente. Errunza e Losq (1985) mostram que, sob a hipótese de idêntica aversão a risco de locais e estrangeiros, os ativos serão precificados conforme a equação (4), valendo, portanto, a equação (5) para a reprecificação dos ativos.

Desta forma, os ativos são reprecificados de forma equivalente ao caso de integração completa. A intuição para este resultado é que os investidores restritos procurarão diversificar seu portfólio entre os ativos inelegíveis e uma proxy do portfólio de ativos elegíveis, que é fornecido através do investimento dos investidores irrestritos. Os investidores irrestritos atuam como se fossem intermediários financeiros neste caso (Errunza e Losq, 1985). 


\section{CARACTERIZAÇÃO DO CHOQUE}

Nesta sessão, será explicado como a concessão de grau de investimento se caracteriza como uma integração parcial, explicada em duas etapas.

A primeira etapa destina-se a descrever como o problema de home bias pode funcionar como segmentação para os investidores locais, não sendo alterado pela concessão de grau de investimento.

É importante que haja segmentação do investidor local em relação ao mercado global. Sem esta hipótese, os investidores locais seriam integrados com o mercado global e, mesmo sob a segmentação dos investidores globais em relação ao mercado local, seria de uma integração parcial, e, conforme a seção anterior, os ativos seriam precificados conforme uma integração completa. Portanto, neste caso, o choque de integração do investidor global com o mercado interno seria irrelevante.

Na segunda etapa, mostra-se como a concessão de grau de investimento tem a função de integrar o mercado doméstico com o global, através do investidor global. Somado à segmentação imposta pelo home bias, tem-se um choque que altera a percepção de risco sistemático.

\subsection{Segmentação Local}

Feldstein e Horioka (1980) mostram que a taxa de poupança nacional é altamente correlacionada com a taxa de investimento nacional, para médias de longos períodos destes valores, utilizando uma regressão cross-sectional. O coeficiente de inclinação de 0,89 é interpretado no trabalho como o coeficiente de retenção de poupança.

Rogoff e Obstfeld (1996) destacam que essa inclinação caiu ao longo do tempo e já era mais baixa em 1996 - 0,6 para países da OECD -, entretanto, ainda alta e significante. São várias as razões encontradas na literatura para explicar a alta retenção mencionada, porém ora se suportam em hipóteses frágeis, ora apresentam contradições empíricas. 
No que tange o mercado de capitais, dados mostram que no final da década de 1980, os Estados Unidos detinham 94\% de seus investimentos nos mercados de capitais dentro dos Estados Unidos, enquanto que para o Japão a retenção era de 98\%, conforme observam French e Poterba (1991). Rogoff e Obstfeld (1996) destacam que a diversificação ainda é muito pequena, embora tenha se elevado desde período mencionado.

As potenciais explicações variam entre bens não comercializáveis, assimetria de informação, problema de dados ou custos de transação. Rogoff e Obstfeld (1996) utilizam um modelo de custos de transação no mercado de bens e encontram resultados semelhantes aos encontrados nos dados, sob determinados valores ${ }^{6}$ de elasticidade de substituição entre bens (locais e estrangeiros) e custos de transação entre estes.

É, portanto, plausível que, mesmo sob pouca ou nenhuma restrição de investimento no exterior, e sob alguma restrição do investidor estrangeiro em relação ao mercado local, o mercado doméstico seja segmentado do mercado global. Por conseguinte, é possível que o fator de risco sistemático para o investidor doméstico seja o fator local e que este não dependa da concessão de grau de investimento.

Por que, então, em um cenário de concessão de grau de investimento, o puzzle de viés de investimento local não valeria? Por que o fator de risco sistemático passa a ser o mercado global e não o mercado local do investidor externo? A resposta para essa pergunta reside em duas constatações: neste cenário, a soma de investimentos estrangeiros seria significante; e para a fração de investidores que investem fora do seu país parece ser razoável supor que o parâmetro de risco seja o mercado global. Portanto, para a precificação do ativo, no cenário de investimento externo no país, vale o mercado global.

\footnotetext{
${ }^{6}$ Ver Rogoff e Obstfled (1996) para observar sob quais circunstâncias o modelo explica o puzzle de viés de ativos domésticos.
} 


\subsection{Grau de investimento}

Existem restrições de investimento em fundos de pensão e fundos mútuos com base na qualidade do ativo. Cantor e Packer (1996) encontram efeitos imediatos na precificação de títulos soberanos quando ocorre uma mudança de classificação de risco do emissor quando este não é grau de investimento, e o efeito é maior quando existe a concessão deste grau. Ainda, encontram, ao contrário de suas expectativas, que a confirmação tende a ter maior efeito do que o primeiro anúncio. Os autores relacionam seus resultados à maior quantidade informacional em relação a emissores grau de investimento.

Da e Gao (2010) observam que existem restrições de investimento para ativos que não são classificados como grau de investimento para algumas classes de fundos, e que mesmo fundos que não enfrentam restrições legais costumam limitar seus investimentos nessa classe de ativos. Encontram, ainda, que a redução de classificação que resulte na perda da concessão de grau de investimento reflete no preço dos ativos e em sua liquidez, dado que existe a obrigatoriedade da venda destes ativos.

Kingsen (2006) também observa restrições legais e em políticas de investimento de fundos para ativos que não possuem grau de investimento. $O$ autor observa que raramente existe distinção dentro de um grupo de classificações, por exemplo, dentro do grupo grau de investimento e que a melhor forma de testar os efeitos da regulação é observar a concessão de grau de investimento ou sua perda.

Chuhan (1994) observa restrições de investimento em relação à qualidade dos ativos no mercado de ações, cuja relevância relativa ao mercado de títulos é destacada pelo autor, embora estas restrições variem entre países e entre as políticas particulares dos investidores institucionais. Segundo o autor, estes investidores se interessam pouco por países cuja classificação seja inferior ao grau de investimento, embora atribua este fato em alguma parte ao nível de qualidade e quantidade informacional que esses países possuem. Outra importante contribuição é a observação de que a indústria de investidores institucionais aos quais as restrições se aplicam é relevante para os mercados emergentes, baseado nos recursos dessa indústria e no valor desses mercados. Por exemplo, em 2010, apenas os 20 maiores fundos de pensão do mundo detinham 5 
trilhões de dólares de patrimônio sob administração, enquanto todas as empresas listas em bolsa no Brasil valem em 20121 trilhão de dólares, e as empresas listadas no Peru em 2011 valiam 120 bilhões de dólares.

Destarte, a elevação da classificação e consequente concessão de grau de investimento a determinado país parece ser importante para os investidores institucionais globais, embora alguns autores destaquem o papel da quantidade e qualidade informacional em relação às restrições, e que mesmo estas não estejam claras, variando entre países, entre indústrias de institucionais e mesmo entre fundos da mesma indústria, em suas políticas de investimento.

Sendo assim, antes da elevação para grau de investimento, considera-se que o fator de risco sistemático para precificação dos ativos seja o mercado local, enquanto que após o evento esse fator seja o mercado global. A concessão atua como um integrador do mercado, antes totalmente segmentado e após em um estado de integração parcial. 


\section{DADOS}

Esta parte do trabalho é dedicada a discutir os dados de forma detalhada. A análise que este trabalho propõe exige os seguintes dados: países e respectivas datas de grau de investimento, histórico de preços dos ativos nos países selecionados e histórico de índices de retorno de mercados locais e mercado global.

Foram selecionados os países que obtiveram ou perderam a concessão de grau de investimento por pelo menos duas das seguintes agências de classificação de risco soberano: S\&P, Fitch e Moody's. A escolha dessas agências se deu por serem as agências mais relevantes, citadas em alguns guias de política de investimento de fundos de pensão, como o fundo de pensão dos funcionários públicos da Califórnia (sexto maior fundo de pensão do mundo em 2010).

As duas primeiras datas de concessão ou perda de grau de investimento são as datas para as regressões base. Analisam-se as duas datas, porque não há uma definição homogênea de grau de investimento para os investidores institucionais. Por exemplo, o fundo de pensão dos bombeiros de Springfield define grau de investimento como duas concessões entre as três agências citadas acima, enquanto que o fundo dos funcionários públicos da Califórnia não deixa claro o número de concessões, e o fundo de pensão dos professores do estado da Califórnia acrescenta a agência Thomson BankWatch. Também não há evidência empírica na literatura de relevância relativa entre os eventos de concessão quanto a sua ordem cronológica de ocorrência.

A Tabela 1 descreve as datas de concessão de grau de investimento para os países selecionados e pelas agências consideradas, enquanto a Tabela 2 descreve as datas de rebaixamento. 
Tabela 1 - Datas de Grau de Investimento por País

\begin{tabular}{lccc} 
& \multicolumn{3}{c}{ Agência de risco } \\
\cline { 2 - 4 } & Standard \& Poor's & Moody's & Fitch \\
\hline Brasil & $30 / \mathrm{abr} / 08$ & $22 / \mathrm{set} / 09$ & $29 / \mathrm{mai} / 08$ \\
Índia & $30 / \mathrm{jan} / 07$ & $22 / \mathrm{jan} / 04$ & $01 / \mathrm{ago} / 06$ \\
México & $07 / \mathrm{fev} / 02$ & $07 / \mathrm{mar} / 00$ & $15 / \mathrm{jan} / 02$ \\
Marrocos & $24 / \mathrm{mar} / 10$ & & $19 / \mathrm{abr} / 07$ \\
Rússia & $31 / \mathrm{jan} / 05$ & $08 / \mathrm{out} / 03$ & $18 / \mathrm{nov} / 04$ \\
Coréia do Sul & $25 / \mathrm{jan} / 99$ & $12 / \mathrm{fev} / 99$ & $19 / \mathrm{jan} / 99$ \\
Peru & $14 / \mathrm{ju} / 08$ & $16 / \mathrm{dez} / 09$ & $02 / \mathrm{abr} / 08$ \\
\hline
\end{tabular}

Tabela 2 - Datas de Rebaixamento por País

\begin{tabular}{lccc} 
& \multicolumn{3}{c}{ Agência de risco } \\
\cline { 2 - 4 } & Standard \& Poor's & Moody's & Fitch \\
\hline Grécia & $27 / \mathrm{abr} / 10$ & $14 / \mathrm{jun} / 10$ & $14 / \mathrm{jan} / 11$ \\
Egito & $22 / \mathrm{mai} / 02$ & & $21 / \mathrm{ago} / 02$ \\
\hline
\end{tabular}

As séries históricas de preços foram obtidas na base de dados Bloomberg. O índice mundial considerado foi o MSCI World Total Return Index, enquanto os índices locais são os análogos ao índice global, mas específicos para cada país considerado. A base de dados é denominada em dólares americanos, e tem periodicidade mensal. Todos os preços são ajustados para pagamentos de $\operatorname{proventos}^{7}$ e deflacionados.

Os retornos são calculados como a primeira diferença entre os logaritmos naturais dos preços dos ativos e dos índices. A partir da série de retornos, são calculados os DIFCOV e a reprecificação.

Os retornos antes e após o evento de concessão ou rebaixamento podem ser escritos conforme (6) e (7), respectivamente.

$$
\begin{aligned}
& E\left[R_{i}\right]=\ln p_{a l v o, i}-\ln p_{i}^{\prime} \\
& E\left[R_{i}^{*}\right]=\ln p_{a l v o, i}-\ln p_{i}^{\prime \prime}
\end{aligned}
$$

\footnotetext{
${ }^{7}$ Os preços são ajustados para que o pagamento de proventos não influencie a série.
} 
Onde:

- $\quad p_{a l v o, i}$ é o preço futuro do ativo i.

- $\quad p_{i}^{\prime}$ é o preço spot do ativo i antes do evento.

- $\quad p_{i}^{\prime \prime}$ é o preço spot do ativo i depois do evento.

Note que o preço futuro é o mesmo antes e depois do evento. Isso ocorre devido às hipóteses de que o investidor se importa apenas com a média e variância dos retornos de seus portfólios e que essas variáveis não são afetadas pelos eventos de concessão de grau de investimento ou rebaixamento. A diferença entre (6) e (7) é dada em (8).

$$
\begin{aligned}
& \Delta R_{i}=E\left[R_{i}\right]-E\left[R_{i}^{*}\right]=\ln p_{a l v o, i}-\ln p_{i}^{\prime}-\left(\ln p_{\text {alvo }, i}-\ln p_{i}^{\prime \prime}\right) \\
& =\ln p_{i}^{\prime \prime}-\ln p_{i}^{\prime}=\Delta \ln P_{i}
\end{aligned}
$$

A diferença entre os preços em torno do evento de concessão de grau de investimento ou rebaixamento oferece uma medida da variação do retorno. É plausível que se queira obter uma medida do retorno referente ao evento apenas, isto é, o retorno não esperado do ativo no período. Desconta-se a média dos retornos para obter-se esta medida. Para o cálculo da média são necessários, no mínimo, 30 observações de retornos.

Para o cálculo da diferença de preços, utilizou-se a janela do mês do evento. O preço de fechamento do mês anterior à concessão do grau de investimento ou ao rebaixamento é o preço spot antes do evento, enquanto que o preço de fechamento do mês em que ocorreu o evento é o preço spot depois do evento.

A variável DIFCOV, conforme explicado, é a diferença de duas covariâncias. Estas covariâncias são calculadas utilizando, no mínimo, 30 observações.

O número de firmas em cada uma das datas analisadas depende da quantidade de firmas para as quais se tem informação suficiente. Entretanto, os resultados foram controlados 
pelas observações e não apresentaram resultados distintos. Com o intuito de não desprezar conteúdo informacional, optou-se por utilizar o total de firmas para as quais havia informação em cada uma das datas analisadas.

Tabela 3 - Estatísticas Descritivas

\begin{tabular}{lrrrrr}
\hline \multicolumn{1}{c}{ País } & $\begin{array}{c}\text { Média do Retorno } \\
\text { (não esperado) } \\
\text { Primeiro Evento }\end{array}$ & $\begin{array}{c}\text { Média do Retorno } \\
\text { (não esperado) } \\
\text { Segundo Evento }\end{array}$ & $\begin{array}{c}\text { Média DIFCOV } \\
\text { - Primeiro } \\
\text { Evento }\end{array}$ & $\begin{array}{c}\text { Média DIFCOV } \\
\text { - Segundo } \\
\text { Evento }\end{array}$ & Observações \\
\hline Brasil & 0.0417 & 0.0725 & 0.0064 & 0.0064 & 238 \\
Índia & -0.1733 & 0.0773 & 0.0051 & 0.0032 & 2,122 \\
México & 0.0334 & 0.0862 & 0.0100 & 0.0088 & 45 \\
Marrocos & 0.0961 & -0.0083 & 0.0022 & 0.0013 & 62 \\
Rússia & -0.1165 & -0.1141 & 0.0203 & 0.0057 & 6 \\
Coréia do Sul & 0.1602 & 0.1602 & 0.0195 & 0.0195 & 455 \\
Peru & -0.0908 & -0.1069 & 0.0030 & 0.0031 & 43 \\
Grécia & -0.1342 & -0.0104 & 0.0050 & 0.0049 & 235 \\
Egito & 0.0637 & 0.0654 & 0.0020 & 0.0016 & 60 \\
\hline Elevação & -0.0564 & 0.0852 & 0.0087 & 0.0060 & 2,971 \\
Rebaixamento & -0.0978 & 0.0040 & 0.0044 & 0.0043 & 295 \\
\hline
\end{tabular}




\section{CONEXÃO ENTRE DADOS E TEORIA}

Ao observar a equação (5), nota-se que segundo a teoria, quando ocorre reprecificação devido à alteração na percepção da fonte de risco sistemático, a magnitude da diferença nos preços será tão maior quanto maior for o seu DIFCOV e na mesma direção, no caso de um evento de concessão de grau de investimento.

No caso contrário, quando o evento é o rebaixamento de grau de investimento, é fácil provar utilizando a mesma técnica que a reprecificação será proporcional ao DIFCOV, em direção oposta.

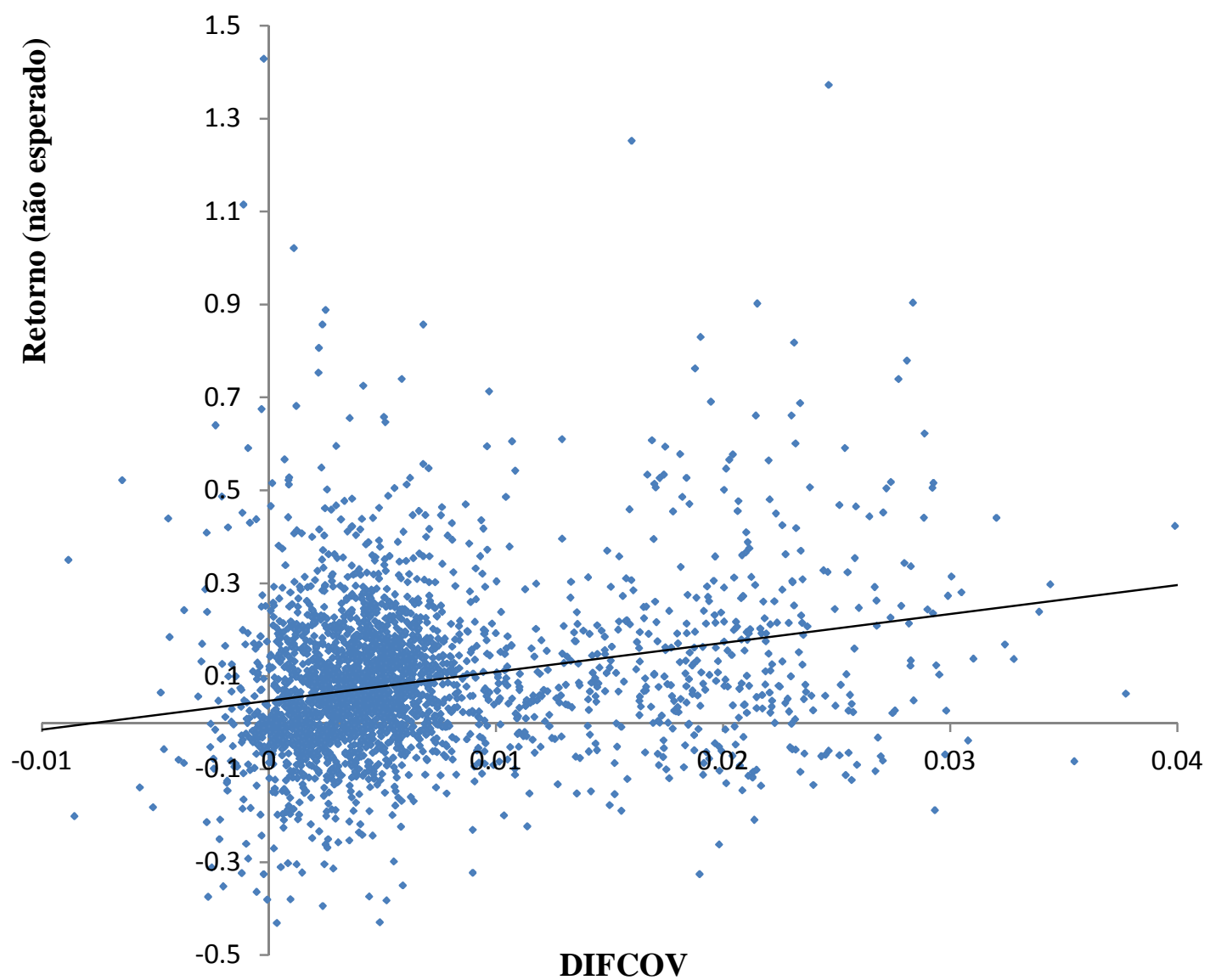

Gráfico 1 - Segunda Elevação para Grau de Investimento 
O Gráfico 1 revela a relação positiva que existe entre a resposta dos preços à integração e a variável DIFCOV, para o caso de eventos de elevação de classificação. O eixo das ordenadas revela o valor da parte não esperada do retorno, que é o retorno no mês da concessão de grau de investimento, neste caso a concessão pela segunda agência de classificação de risco, subtraído do retorno médio observado. A intuição de utilizar a parcela não esperada do retorno é obter apenas o retorno provocado pela mudança na percepção da fonte de risco sistemático. O eixo das abscissas revela o valor do DIFCOV.

A equação (9) representa a relação entre a reprecificação e DIFCOV para elevação de classificação, apresentada no Gráfico 1.

$$
\begin{aligned}
& \Delta R_{i j}=\Delta \ln P_{i j} \underset{(11,58)}{0,0481+\underset{(13,42)}{6,168^{*}} \operatorname{DIFCOV} V_{i j}} \\
& \text { R-quadrado }=0,058 \\
& \text { Observações }=2917
\end{aligned}
$$

Onde $\Delta \ln P_{i j}$ é a parcela não esperada do retorno no mês do evento.

A equação (9) e o Gráfico 1 mostram o que se esperava ao examinar a teoria: uma relação positiva entre a reprecificação e a variável DIFCOV. A equação (6) ainda revela que esta relação é estatisticamente significante. Portanto, nesta análise preliminar os resultados confirmam que firmas que experimentam maior impacto de mudança no nível de exposição ao risco sistemático sofrem maior impacto nos retornos esperados.

O Gráfico 2 representa a dispersão do retorno e DIFCOV para o evento de rebaixamento de grau de investimento - neste caso o segundo rebaixamento -, de forma análoga ao Gráfico 1.

Como na equação (9), a relação estatística entre a parcela não esperada do retorno e DIFCOV é dada na equação (10), para rebaixamento de classificação abaixo do grau de investimento. 


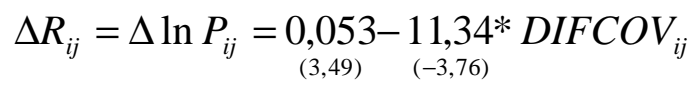

R-quadrado $=0,0434$

Observações $=290$

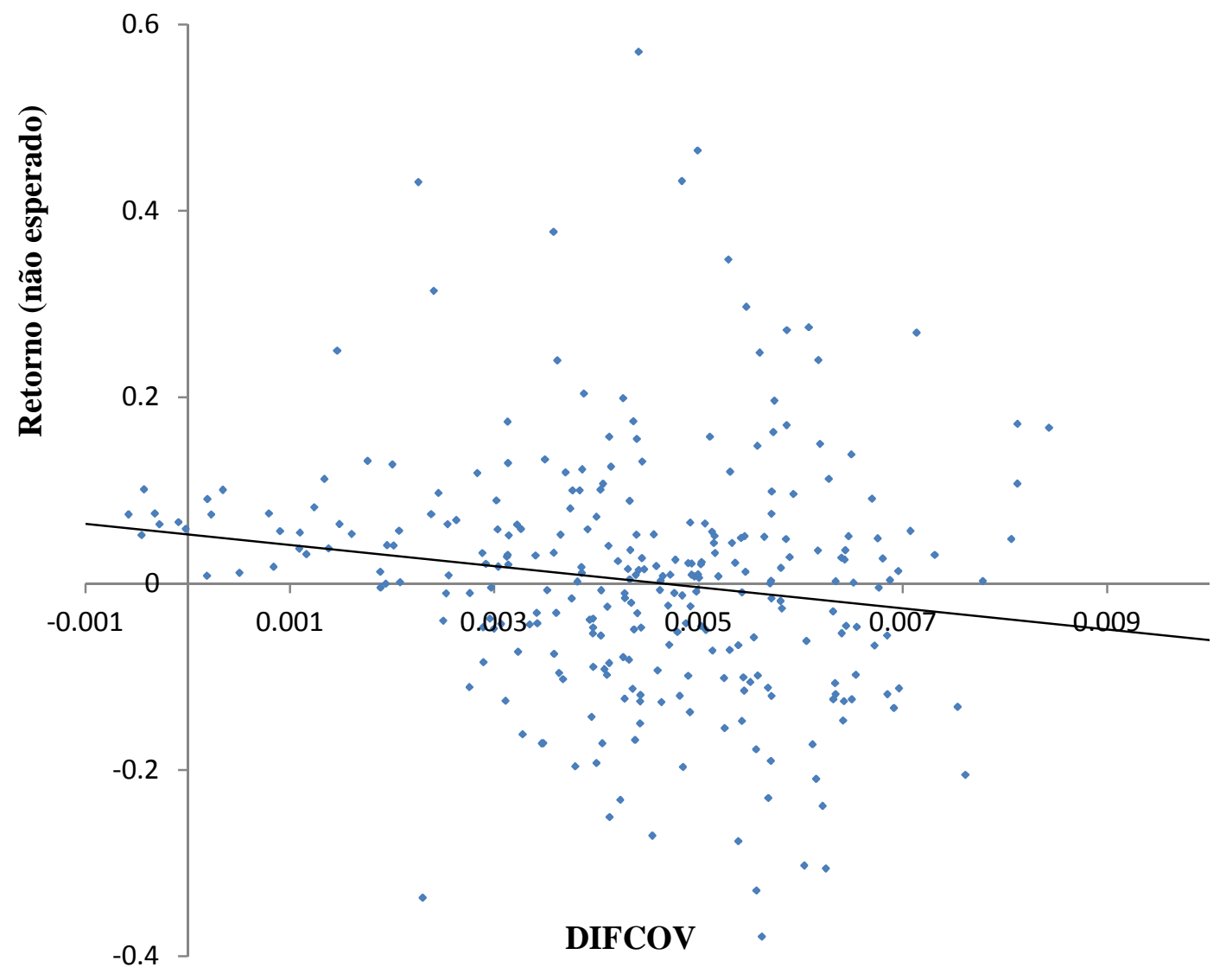

Gráfico 2 - Segundo Rebaixamento de Grau de Investimento

Assim como o caso de elevação de classificação, o caso de rebaixamento também vai ao encontro do que se esperava ao examinar a teoria: quanto maior é o DIFCOV da firma, maior o choque no retorno esperado que esta experimenta. Ainda, na equação (10) é possível notar que esta relação é estatisticamente significante. 


\section{MODELO E RESULTADOS}

O modelo descrito pela regressão (11) é a forma de investigar se existe relação entre as respostas nos preços à concessão de grau de investimento, ou sua perda, e a diferença em nível de exposição ao risco, além da diferença nas taxas de risco, desiguais entre países.

$$
\text { eret }_{i j}=\alpha+\beta \cdot \operatorname{DIFCOV} V_{i j}+C_{j}+\mu_{i j}
$$

Onde:

- $\quad$ eret $_{i j}$ é o retorno não esperado da ação da empresa i do país j durante o mês do grau de investimento.

- $C_{j}$ é a dummy que permite identificar o efeito fixo específico para o país j.

A estimação conjunta especificada facilita testar o que se propõe. A constante de estimação $\alpha$ impõe que os efeitos da mudança da taxa livre de risco sejam os mesmos para todas as empresas depois de controlado o efeito fixo por país. Como $\beta$ mensura o efeito da diversificação de risco imposta pelo anúncio da mudança de classificação, espera-se que seja positivo para o evento de elevação e negativo para o evento de rebaixamento. Conforme mencionado, as constantes carregam informações específicas de cada país, o que torna o exercício de suas interpretações impreciso, não sendo necessariamente associado à mudança específica na taxa livre de risco por país. É importante ressaltar que o efeito por país é a soma da dummy correspondente com a constante, exceto para o país cuja dummy é omitida - neste caso o efeito é apenas a constante.

A Tabela 4 evidencia os resultados encontrados para as regressões em torno do primeiro e do segundo evento de elevação da nota. Os resultados mostram que para o segundo o evento, quando há mudança no nível do risco sistemático, as firmas com maior 
exposição à diferença - maior DIFCOV - experimentam maiores impactos em seus retornos esperados - maior reprecificação. A diversificação de risco, portanto, é importante para explicar a reprecificação dos ativos no caso do choque da segunda elevação.

Este resultado vai ao encontro do resultado encontrado em Chari e Henry (2004). O coeficiente encontrado neste trabalho é da mesma ordem de grandeza daquele encontrado por Chari e Henry em sua regressão base: 8,14 e 3,59, respectivamente.

Tabela 4 - Primeiro e Segundo Evento de Elevação de Nota

\begin{tabular}{|c|c|c|}
\hline & $\begin{array}{l}\text { Primeira } \\
\text { Elevação }\end{array}$ & $\begin{array}{l}\text { Segunda } \\
\text { Elevação }\end{array}$ \\
\hline Variáveis & eret & eret \\
\hline DIFCOV & $\begin{array}{c}2.217 \\
(3.150)\end{array}$ & $\begin{array}{c}\mathbf{8 . 1 4 0} * * \\
(2.463)\end{array}$ \\
\hline Índia & $\begin{array}{l}-\mathbf{0 . 2 1 2} * * * \\
(0.00421)\end{array}$ & $\begin{array}{c}\mathbf{0 . 0 3 0 2} * * * \\
(0.00770)\end{array}$ \\
\hline Coréia do Sul & $\begin{array}{l}\mathbf{0 . 0 8 9 7} * \\
(0.0410)\end{array}$ & $\begin{array}{l}\mathbf{- 0 . 0 1 9 0} \\
(0.0323)\end{array}$ \\
\hline Marrocos & $\begin{array}{c}\mathbf{0 . 0 6 3 8} * * * \\
(0.0133)\end{array}$ & $\begin{array}{c}\mathbf{- 0 . 0 3 9 7 * *} \\
(0.0124)\end{array}$ \\
\hline México & $\begin{array}{l}\mathbf{- 0 . 0 1 6 2} \\
(0.0113)\end{array}$ & $\begin{array}{l}\mathbf{- 0 . 0 0 6 1 5} \\
(0.00600)\end{array}$ \\
\hline Peru & $\begin{array}{c}-\mathbf{0 . 1 2 5} * * * \\
(0.0109)\end{array}$ & $\begin{array}{l}\mathbf{- 0 . 1 5 3} * * * \\
(0.00794)\end{array}$ \\
\hline Rússia & $\begin{array}{c}\mathbf{- 0 . 1 8 9} * * * \\
(0.0436)\end{array}$ & $\begin{array}{l}\mathbf{- 0 . 1 8 2} * * * \\
(0.00152)\end{array}$ \\
\hline Constante & $\begin{array}{c}\mathbf{0 . 0 2 7 4} \\
(0.0203)\end{array}$ & $\begin{array}{c}\mathbf{0 . 0 2 0 8} \\
(0.0156)\end{array}$ \\
\hline Observações & $1,909.00$ & $2,917.00$ \\
\hline R-quadrado & 0.330 & 0.082 \\
\hline
\end{tabular}

A Tabela 5 apresenta os resultados para o caso de rebaixamento, no qual também se observa explicação estatística da magnitude da diferença do nível de exposição ao risco sistemático nos retornos esperados apenas para o segundo evento, embora a significância neste caso seja de 10\%. A variável DIFCOV, portanto, mostrou-se relevante para a reavaliação dos ativos na ocasião do segundo evento, seja este concessão ou rebaixamento. 
No que tange a diferença de resultados entre o primeiro e segundo evento, os resultados são coerentes com aqueles observados em Canton e Packer (1996), que encontraram impactos maiores na confirmação de uma alteração de classificação de risco soberano do que na sua primeira alteração. Ainda, conforme mencionado, a regulação não é única e alguns investidores institucionais definem suas restrições de qualidade de portfólio com a necessidade de concessão de grau de investimento por duas agências.

Tabela 5 - Primeiro e Segundo Evento de Rebaixamento de Nota

\begin{tabular}{l|c|c}
\hline & $\begin{array}{c}\text { Primeiro } \\
\text { Rebaixamento }\end{array}$ & $\begin{array}{c}\text { Segundo } \\
\text { Rebaixamento }\end{array}$ \\
\hline VIFCOriáveis & eret & eret \\
Grécia & $\mathbf{- 1 4 . 2 3}$ & $\mathbf{- 7 . 3 7 1 *}$ \\
& $(4.026)$ & $(0.896)$ \\
Constante & $\mathbf{- 0 . 1 5 6 * *}$ & $\mathbf{- 0 . 0 5 1 1 * *}$ \\
& $(0.0118)$ & $(0.00300)$ \\
Observações & $\mathbf{0 . 0 9 2 6 *}$ & $\mathbf{0 . 0 7 7 0 * *}$ \\
R-quadrado & $(0.00820)$ & $(0.00141)$ \\
Erros padrões entre parênteses & 290 \\
*** p<0.01, ** $\mathrm{p}<0.05, * \mathrm{p}<0.1$ & 0.063 \\
\hline
\end{tabular}

É possível que haja antecipação do evento de elevação ou rebaixamento da nota. Neste caso, a reprecificação observada mediria apenas parte do efeito de reprecificação. Ou seja, se há antecipação, os resultados observados subestimam o efeito real da variável DIFCOV na explicação da reprecificação.

No caso de existência de endogeneidade, o choque comum a cada país captura o viés, a menos que haja correlação da endogeneidade com as covariâncias específicas de cada firma que medem a diferença de exposição ao risco sistemático.

Ainda, é possível que os retornos das firmas estejam correlacionados dentro de um mesmo país, já que o respectivo evento é comum entre estas. Por esta razão, os resultados são corrigidos ao se permitir que os elementos fora da diagonal principal da matriz de variância-covariância, para países de um mesmo país, sejam diferentes de zero. 
Outra possibilidade é a existência de pressão nos preços devido aos eventos. No entanto, assim como no caso da endogeneidade, a pressão só é um problema se estiver correlacionada com a variável DIFCOV e, embora seja provável que a entrada ou saída de capitais possa fazer pressão nos preços, não é claro que essa correlação exista. Tampouco que, na existência de alguma relação, esta seja positiva, caso em que o efeito da diversificação observado estaria superestimado.

Realizaram-se outras regressões com o intuito de investigar efeitos anteriores ou posteriores ao evento, ou efeitos que fossem prolongados por mais que os 30 dias da janela da regressão base apresentada. Além disso, realizaram-se regressões com o retorno total na janela, além da parcela não esperada do retorno.

As Tabelas 6 e 7 apresentam os resultados das regressões adicionais para os casos de integração e segmentação, respectivamente. Cada tabela contém 8 colunas, uma para cada regressão. As regressões (1) e (5) são as regressões do primeiro e segundo evento, respectivamente. As regressões (2) e (6) são realizadas para as mesmas datas de (1) e (5), entretanto considera-se uma janela de 2 meses: o retorno e o retorno não esperado são calculados entre o mês subsequente e o mês anterior ao anúncio de alteração de classificação.

As regressões (3) e (4) são realizadas para datas base de dois e quatro meses antes do primeiro evento, respectivamente. As regressões (7) e (8) são para datas base de dois e quatro meses após o segundo evento, respectivamente. As janelas dessas regressões são de 1 mês.

Observa-se que ao tornar as janelas de observação maiores em torno dos eventos, as explicações estatísticas encontradas nas janelas da regressão base não aparecem para o segundo evento. É de se esperar que para janelas suficientemente grandes, a mudança no nível de exposição ao risco sistemático tenha impacto relativo insignificante nos retornos.

Quando não há mudança de exposição ao risco sistemático, a variável DIFCOV não deve ter impacto sobre os retornos. Desta forma, dois resultados são destacáveis: a 
regressão de dois meses após o segundo evento para o choque de integração e a regressão de dois meses antes do primeiro evento para o choque de segmentação.

Não se encontrou qualquer evento comum aos países da amostra que explicasse o resultado destacado para o choque de integração. Pode ser que haja algum efeito da diversificação após a concessão.

Em relação ao resultado destacado para o choque de segmentação, é possível que os eventos destacados a seguir o expliquem. Segundo Bagus (2010), em fevereiro de 2010 se tornou público que o governo grego havia mascarado o real tamanho do seu déficit através de derivativos. Ainda, em 24 do mesmo fevereiro, a Standard \& Poor's declarou que poderia reduzir a classificação da Grécia em até dois níveis dentro de um mês. Como a amostra contém apenas dois países e fevereiro é o mês do caso (3) da Tabela 4 para um destes países, é possível que a explicação resida nos acontecimentos narrados acima.

Conforme se esperava segundo a teoria, as demais regressões, para os dois casos, não tiveram significância no sentido das predições teóricas.

Por fim, os resultados confirmam que os retornos específicos dos ativos são alterados de acordo com as respectivas magnitudes individuais das diferenças de nível de exposição ao risco sistemático, indo ao encontro das predições teóricas. Confirmaram-se os resultados de Chari e Henry (2004) para um choque de integração. Observou-se, ainda, um resultado novo e interessante: quando o choque ocorre na direção inversa, isto é, de integração para segmentação, as diferenças específicas de nível de exposição ao risco sistemático de cada firma também explicam as reprecificações, demonstrando a importância da diversificação de risco na precificação de ativos. 
Tabela 6 - Resultados Adicionais para o Choque de Integração

\begin{tabular}{|c|c|c|c|c|c|c|c|c|c|c|c|c|c|c|c|c|}
\hline \multirow[b]{2}{*}{ Variáveis } & \multicolumn{2}{|c|}{ (1) } & \multicolumn{2}{|c|}{ (2) } & \multicolumn{2}{|c|}{ (3) } & \multicolumn{2}{|c|}{ (4) } & \multicolumn{2}{|c|}{ (5) } & \multicolumn{2}{|c|}{ (6) } & \multicolumn{2}{|c|}{ (7) } & \multicolumn{2}{|c|}{ (8) } \\
\hline & retorno & Eret & retorno & eret & retorno & eret & retorno & eret & retorno & eret & retorno & eret & retorno & eret & retorno & eret \\
\hline \multirow[t]{2}{*}{ DIFCOV } & 1.260 & 2.217 & -2.505 & -1.546 & 7.180 & $8.027^{\star}$ & $-5.572^{\star \star}$ & $-4.555^{\star}$ & $7.335^{\star \star}$ & $8.140^{\star \star}$ & 6.81 & 7.612 & $2.317^{\star \star \star}$ & $3.037^{\star \star \star}$ & -0.751 & -0.0116 \\
\hline & (3.318) & (3.150) & (3.798) & (3.670) & $(4.123)$ & (3.982) & (2.032) & $(2.110)$ & (2.388) & (2.463) & $(4.645)$ & (4.699) & $(0.400)$ & $(0.272)$ & (1.229) & (1.429) \\
\hline \multirow[t]{2}{*}{ Índia } & $-0.237^{\star \star \star}$ & $-0.212^{\star \star \star}$ & $-0.422^{\star \star \star}$ & $-0.397^{\star \star \star}$ & $0.258^{\star \star \star}$ & $0.279^{\star \star \star}$ & $0.0206^{\star \star *}$ & 0.00596 & $0.0228^{\star \star}$ & $0.0302^{\star \star \star}$ & $0.121^{\star \star \star}$ & $0.129^{\star \star \star}$ & $0.111^{\star \star \star}$ & $0.116^{\star \star \star}$ & $0.343^{\star \star \star}$ & $0.340^{\star \star \star}$ \\
\hline & $(0.00444)$ & $(0.00421)$ & $(0.00492)$ & $(0.00475)$ & $(0.00556)$ & $(0.00537)$ & $(0.00303)$ & $(0.00314)$ & $(0.00746)$ & $(0.00770)$ & $(0.0146)$ & $(0.0148)$ & $(0.00129)$ & $(0.000875)$ & $(0.00571)$ & $(0.00664)$ \\
\hline \multirow[t]{2}{*}{ Coréia do Sul } & 0.0633 & $0.0897^{\star}$ & $-0.136^{\star \star}$ & $-0.110^{\star}$ & $0.353^{\star \star \star}$ & $0.379^{\star \star \star}$ & $0.0748^{\star \star}$ & $0.111^{\star \star \star}$ & -0.0464 & -0.0190 & $-0.141^{\star}$ & -0.114 & $0.142^{\star \star \star}$ & $0.162^{\star \star \star}$ & $0.294^{\star \star \star}$ & $0.305^{\star \star \star}$ \\
\hline & $(0.0432)$ & $(0.0410)$ & $(0.0498)$ & $(0.0481)$ & $(0.0550)$ & $(0.0532)$ & $(0.0239)$ & $(0.0248)$ & $(0.0313)$ & $(0.0323)$ & $(0.0611)$ & $(0.0619)$ & $(0.00571)$ & $(0.00388)$ & $(0.0153)$ & $(0.0178)$ \\
\hline \multirow[t]{2}{*}{ Marrocos } & $0.0512^{\star \star}$ & $0.0638^{\star \star \star}$ & $-0.119^{\star \star \star}$ & $-0.106^{\star \star \star}$ & $0.186^{\star \star \star}$ & $0.198^{\star \star \star}$ & $0.0807^{\star \star \star}$ & $0.0943^{\star \star \star}$ & $0.0593^{\star \star \star}$ & $-0.0397^{\star \star}$ & 0.0424 & $0.0620^{\star *}$ & $0.0104^{\star \star \star}$ & $0.0287^{\star \star \star}$ & $0.330^{\star \star \star}$ & $0.342^{\star \star \star}$ \\
\hline & $(0.0140)$ & $(0.0133)$ & $(0.0159)$ & $(0.0153)$ & $(0.0181)$ & $(0.0175)$ & $(0.00902)$ & $(0.00936)$ & $(0.0121)$ & $(0.0124)$ & $(0.0235)$ & $(0.0237)$ & $(0.00204)$ & $(0.00138)$ & $(0.00794)$ & $(0.00923)$ \\
\hline \multirow[t]{2}{*}{ México } & $-0.0359^{\star *}$ & -0.0162 & $-0.213^{\star \star \star}$ & $-0.193^{\star \star \star}$ & $0.0578^{\star \star \star}$ & $-0.0399^{* *}$ & $0.243^{\star \star \star}$ & $0.259^{\star \star \star}$ & $0.0313^{\star \star \star}$ & -0.00615 & $0.0240^{\star}$ & $0.0492^{\star \star \star}$ & $0.128^{\star \star \star}$ & $0.150^{\star \star *}$ & $0.269^{\star \star \star}$ & $0.285^{\star \star \star}$ \\
\hline & $(0.0119)$ & $(0.0113)$ & $(0.0137)$ & $(0.0133)$ & $(0.0154)$ & $(0.0149)$ & $(0.00837)$ & $(0.00869)$ & $(0.00582)$ & $(0.00600)$ & $(0.0113)$ & $(0.0115)$ & $(0.000712)$ & $(0.000484)$ & $(0.000433)$ & $(0.000504)$ \\
\hline \multirow[t]{2}{*}{ Peru } & $-0.120^{\star \star \star}$ & $-0.125^{\star \star \star}$ & $-0.216^{\star \star \star}$ & $-0.221^{\star \star \star}$ & $0.239^{\star \star \star}$ & $0.232^{\star \star \star}$ & $0.0470^{\star \star \star}$ & $0.0392^{\star \star \star}$ & $-0.151^{\star \star \star}$ & $-0.153^{\star \star \star}$ & $-0.192^{\star \star \star}$ & $-0.193^{\star \star \star}$ & $-0.0678^{\star \star \star}$ & $-0.0689^{\star \star \star}$ & $0.339^{\star \star \star}$ & $0.336^{\star \star \star}$ \\
\hline & $(0.0115)$ & $(0.0109)$ & $(0.0130)$ & $(0.0126)$ & $(0.0147)$ & $(0.0142)$ & $(0.00721)$ & $(0.00749)$ & $(0.00770)$ & $(0.00794)$ & $(0.0152)$ & $(0.0153)$ & $(0.00125)$ & $(0.000847)$ & $(0.00368)$ & $(0.00428)$ \\
\hline \multirow[t]{2}{*}{ Rússia } & $-0.166^{\star \star}$ & $-0.189^{\star * *}$ & $-0.268^{\star \star \star}$ & $-0.297^{\star \star \star}$ & 0.108 & 0.0821 & $0.193^{\star \star \star}$ & $0.164^{\star \star *}$ & $-0.167^{\star \star \star}$ & $-0.182^{\star \star \star}$ & $-0.111^{\star \star *}$ & $-0.126^{\star \star \star}$ & $0.0777^{\star \star \star}$ & $0.0603^{\star \star *}$ & $0.267^{\star \star \star}$ & $0.245^{\star \star \star}$ \\
\hline & $(0.0459)$ & $(0.0436)$ & $(0.00592)$ & $(0.00572)$ & $(0.0575)$ & $(0.0556)$ & $(0.0290)$ & $(0.0301)$ & $(0.00147)$ & $(0.00152)$ & $(0.00286)$ & $(0.00290)$ & $(0.000473)$ & $(0.000322)$ & $(0.00327)$ & $(0.00380)$ \\
\hline \multirow[t]{2}{*}{ Constante } & $0.0539^{\star *}$ & 0.0274 & $0.170^{\star * *}$ & $0.144^{\star \star *}$ & $-0.130^{\star \star *}$ & $-0.154^{\star * *}$ & $-0.0447^{\star *}$ & $0.0690^{\star \star \star}$ & $0.0454^{\star \star}$ & 0.0208 & -0.00643 & -0.0310 & $-0.0512^{\star \star *}$ & $-0.0738^{\star \star \star}$ & $-0.296^{\star \star \star}$ & $-0.311^{\star \star \star}$ \\
\hline & $(0.0214)$ & $(0.0203)$ & $(0.0243)$ & $(0.0235)$ & $(0.0270)$ & $(0.0261)$ & $(0.0133)$ & $(0.0138)$ & $(0.0152)$ & $(0.0156)$ & $(0.0295)$ & $(0.0298)$ & $(0.00255)$ & $(0.00173)$ & $(0.00949)$ & $(0.0110)$ \\
\hline Observações & 1,909 & 1,909 & 1,900 & 1,900 & 1,850 & 1,850 & 1,831 & 1,831 & 2,917 & 2,917 & 2,935 & 2,935 & 2,961 & 2,961 & 2,971 & 2,971 \\
\hline R-quadrado & 0.315 & 0.330 & 0.259 & 0.258 & 0.289 & 0.313 & 0.047 & 0.048 & 0.056 & 0.082 & 0.097 & 0.086 & 0.086 & 0.115 & 0.192 & 0.187 \\
\hline
\end{tabular}

Erros padrões entre parênteses

${ }^{* * *} p<0.01,{ }^{* *} p<0.05,{ }^{*} p<0.1$
(1) Primeiro evento. Janela de um mês.
(3) 2 meses antes do primeiro evento. Janela de um mês.
(2) Primeiro evento. Janela de dois meses.
(4) 4 meses antes do primeiro evento. Janela de um mês.
(7) Dois meses após o segundo evento. Janela de um mês.

(5) Segundo evento. Janela de um mês.

(6) Segundo evento. Janela de dois meses.

(8) Quatro meses após o segundo evento. Janela de um mês. 
Tabela 7 - Resultados Adicionais para o Choque de Segmentação

\begin{tabular}{|c|c|c|c|c|c|c|c|c|c|c|c|c|c|c|c|c|}
\hline \multirow[b]{2}{*}{ Variáveis } & \multicolumn{2}{|c|}{ (1) } & \multicolumn{2}{|c|}{ (2) } & \multicolumn{2}{|c|}{ (3) } & \multicolumn{2}{|c|}{ (4) } & \multicolumn{2}{|c|}{ (5) } & \multicolumn{2}{|c|}{ (6) } & \multicolumn{2}{|c|}{ (7) } & \multicolumn{2}{|c|}{ (8) } \\
\hline & retorno & Eret & retorno & eret & retorno & eret & retorno & eret & retorno & eret & retorno & eret & retorno & eret & retorno & eret \\
\hline \multirow[t]{2}{*}{ DIFCOV } & -17.07 & -14.23 & -35.18 & -32.34 & $-9.835^{\star \star}$ & $-7.379^{\star \star}$ & -7.264 & -5.416 & $-8.417^{\star \star}$ & $-7.371^{\star}$ & 0.124 & 1.170 & -2.575 & -1.426 & -1.572 & -0.304 \\
\hline & $(4.581)$ & $(4.026)$ & $(10.05)$ & $(9.499)$ & $(0.708)$ & $(0.152)$ & $(1.862)$ & (3.475) & $(0.536)$ & $(0.896)$ & $(9.083)$ & $(10.52)$ & $(3.446)$ & $(2.381)$ & $(0.990)$ & $(0.119)$ \\
\hline \multirow[t]{2}{*}{ Grécia } & $-0.127^{\star}$ & $-0.156^{\star \star}$ & $-0.247^{\star}$ & $-0.277^{\star}$ & $-0.0649^{\star \star}$ & $-0.0958^{\star \star \star}$ & -0.00794 & -0.0389 & $-0.0286^{\star \star}$ & $-0.0511^{\star \star}$ & 0.138 & 0.116 & -0.0227 & -0.0460 & $0.0392^{\star}$ & $0.0139^{\star *}$ \\
\hline & $(0.0134)$ & $(0.0118)$ & $(0.0294)$ & $(0.0278)$ & $(0.00178)$ & $(0.000382)$ & $(0.00488)$ & $(0.00911)$ & $(0.00180)$ & $(0.00300)$ & $(0.0305)$ & $(0.0353)$ & $(0.0120)$ & $(0.00828)$ & $(0.00361)$ & $(0.000435)$ \\
\hline \multirow[t]{2}{*}{ Constante } & $0.0678^{\star}$ & $0.0926^{\star}$ & 0.0943 & 0.119 & $0.0219^{\star \star}$ & $0.0484^{\star \star \star}$ & 0.0132 & 0.0421 & $0.0502^{\star \star}$ & $0.0770^{\star \star}$ & 0.00656 & 0.0333 & -0.0220 & 0.00381 & $-0.0142^{\star}$ & $0.0131^{\star \star \star}$ \\
\hline & $(0.00933)$ & $(0.00820)$ & $(0.0205)$ & $(0.0193)$ & $(0.00153)$ & $(0.000328)$ & $(0.00380)$ & $(0.00710)$ & $(0.000844)$ & $(0.00141)$ & $(0.0143)$ & $(0.0165)$ & $(0.00570)$ & $(0.00394)$ & $(0.00142)$ & $(0.000171)$ \\
\hline Observações & 288 & 288 & 288 & 288 & 281 & 281 & 281 & 281 & 290 & 290 & 290 & 290 & 295 & 295 & 295 & 295 \\
\hline R-quadrado & 0.256 & 0.289 & 0.355 & 0.373 & 0.087 & 0.122 & 0.013 & 0.027 & 0.047 & 0.063 & 0.094 & 0.072 & 0.008 & 0.017 & 0.009 & 0.001 \\
\hline
\end{tabular}

Erros padrões entre parênteses

${ }^{* * *} p<0.01,{ }^{* *} p<0.05,{ }^{*} p<0.1$

(1) Primeiro evento. Janela de um

Primeiro evento Janela de dois meses.

Dois meses após (4)

mois

(8) Quatro meses após o segundo evento. Janela de um mês
2 meses antes do primeiro evento. Janela de um mês. 4 meses antes do primeiro evento. Janela de um mês.
(5) Segundo evento. Janela de um mês.

(6) Segundo evento. Janela de dois meses. 


\section{CONCLUSÃO}

Trabalhos anteriores efetuaram testes na teoria de precificação de ativos no nível de exposição ao risco sistemático, com resultado que tanto a refutam como a confirmam. Este trabalho utiliza uma abordagem distinta, no sentido de efetuar teste quando há mudança no grau de risco sistemático. Os resultados deste trabalho confirmam as predições teóricas de que diversificação de risco tem papel relevante na precificação de ativos, e vão ao encontro dos resultados encontrados por Chari e Henry (2004), que também utilizam a metodologia de mudança de nível.

Este trabalho também contribui com um resultado novo: os resultados mostram a confirmação das predições teóricas também para o caso de um choque em direção à segmentação do mercado, além do choque de integração.

Como o efeito específico por país é de difícil interpretação, não foi investigada a relevância relativa do choque comum à diversificação. Como existe informação reduzida para ativos específicos de mercados emergentes, essa pode ser uma investigação interessante e o uso de dados específicos pode contribuir nesta pesquisa.

Chari e Henry (2004) destacam que uma importante questão é a importância dos eventos de integração para o investimento em capital físico. A mudança do grau de risco sistemático pode ser importante para a otimização do risco da produção.

Trabalhos futuros que investiguem os efeitos no mercado de capitais das mudanças de classificação de risco em torno do grau de investimento podem fornecer insumos mais precisos da dinâmica do fluxo de capitais que esses eventos geram, em especial para mercados emergentes. Tais resultados podem melhorar a precisão dos testes e a escolha de metodologia de teste do presente trabalho, podendo alterar os resultados encontrados presentemente. 


\section{REFERÊNCIAS}

BAGUS, Philipp. A Tragédia do Euro. Vide Editorial, 2012.

BANZ, Rolf W. The Relationship Between Return and Market Value of Common Stocks. Journal of Financial Economics. Vol. 9, No. 1, p. 3-18, 1981.

BASU, S. Investment Performance of Common Stocks in Relation to Their Price-Earnings Ratios: A Test of the Efficient Market Hypothesis. The Journal of Finance. Vol. 32, No.3, p. 663-682, 1977.

BASU, S. The Relationship Between Earnings' Yield, Market Value and Return for NYSE Common Stocks: Further Evidence. Journal of Financial Economics. Vol. 12, No. 1, p. 129156, 1983.

BHANDARI, Laxmi C. Debt/Equity Ratio and Expected Common Stock Returns: Empirical Evidence. The Journal of Finance. Vol. 43, No. 2, p. 507-528, 1988.

BLACK, Fischer; JENSEN, Michael; SCHOLES, Myron. The Capital Asset Pricing Model: Some Empirical Tests. In: JENSEN, Michael. Studies in the Theory of Capital Markets. Nova Iorque: Ed. Praeger, 1972.

BLUME, Marshall E.; FRIEND, Irwin. A New Look at the Capital Asset Pricing Model. The Journal of Finance. Vol. 28, No. 1, p. 19-33, 1973.

CAMPBELL, John Y. Asset Pricing at the Millennium. The Journal of Finance. Vol. 55, No. 4, p. 1515-1567, 2000.

CANTOR, Riachard; PACKER, Frank. Determinants and Impact of Sovereign Credit Ratings. Federal Reserve Bank of New York Economic Policy Review. P. 37-54. Outubro de 1996.

CHARI, Anusha; HENRY, Peter B. Risk Sharing and Asset Prices: Evidence from a Natural Experiment. The Journal of Finance. Vol. 59, No. 3, p. 1295-1324, 2004.

CHUHAN, Punam. Are Institutional Investors an Important Source of Portfolio Investment in Emerging Markets? Washington: International Economics Dept, World Bank, 1994.

COCHRANE, John. New facts in finance. Economic Perspectives. Federal Reserve Bank of Chicago 23, p. 36-58, 1999.

ERRUNZA, Vihang; LOSQ, Etienne. International Asset Pricing Under Mild Segmentation: Theory and Test. The Journal of Finance. Vol. 40, p. 105-124. 1985. 
FAMA, Eugene F. Efficient Capital Markets: II. The Journal of Finance. Vol. 46, No. 5, p. 1575-1617, 1991.

FAMA, Eugene F. FRENCH, Kenneth R. The Capital Asset Pricing Model: Theory and Evidence. Journal of Economic Perspectives. Vol. 18, No. 3, p. 25-46, 2004.

FAMA, Eugene F. FRENCH, Kenneth R. The Cross-Section of Expected Stock Returns. Journal of Finance. Vol. 47, No. 2, p. 427-465, 1992.

FAMA, Eugene F.; MACBETH, James D. Risk, Return, and Equilibrium: Empirical Tests. Journal of Political Economics. Vol. 81, No. 3, p. 607-636, 1973.

FELDSTEIN, Martin; HORIOKA, Charles. Domestic Savings and International Capitals Flows. The Economic Journal. V. 40, p. 314-329, 1980.

FRENCH, Keneth R.; POTERBA, James M. Investor Diversification and International Equity Markets. American Economic Review. Vol. 81, p. 222-226, 1991.

HENRY, Peter B. Stock Market Liberalization, Economic Reform, and Emerging Market Equity Prices. The Journal of Finance. Vol. 55, No. 2, p. 529-564, 2000.

KINGSEN, Darren J. Credit Ratings and Capital Structure. The Journal of Finance. Vol. 61, p. 1035-1072, 2006.

OBSTFELD, Maurice; ROGOFF, Keneth. Foundations of International Macroeconomics. Capítulo 5, p. 269-347. Cambridge e Londres: MIT Press, 1996.

ROLL, Richard. A Critique of the Asset Pricing Theory's Tests Part I: On Past and Potential Testability of the Theory. Journal of Financial Economics. Vol. 4, No. 2, p. 129-176, 1977.

SHARPE, William F. Capital Asset Prices: A Theory of Market Equilibrium under Conditions of Risk. The Journal of Finance. Vol. 19, No. 3, p. 425-442,1964.

SHLEIFER, Andrei. Do Demand Curves for Stocks Slope Down? The Journal of Finance. Vol. 41, No.3, p. 579-590, 1985.

STULZ, René M. Globalization of equity markets and the cost of capital. Ohio State University, 1999a.

STULZ, René M. Globalization, corporate finance, and the cost of capital. Journal of Applied Corporate Finance. Vol. 12, No3, p. 8-25, $1999 \mathrm{~b}$.

WHITE, Halbert. A Reality Check for Data Snooping. Econometrica. Vol. 68, No. 5, p. $1097-$ 1126, 2000.

DA, Zhi; GAO, Pengjie. Clientele Change, Persistant Liquidity Shock, and Bond Return Reversals After Rating Downgrade. Journal of Finance and Quantitative Analysis. Vol. 45, No. 1, p. 27-48, 2010. 